\title{
LITERATURE AND HUMAN VALUES: AN EXPERIENCE FROM AN EFL CLASSROOM AT PSU, PATTANI
}

\author{
Suraiya Sulaiman \\ Prince of Songkla University, Pattani, Thailand \\ suraiya.s@psu.ac.th
}

\begin{abstract}
Being a rich source of language and culture, literature has been an ideal tool for the study of a language. As literature offers a bountiful and extremely varied body of written material that deals with enduring human issues, it facilitates in enhancing students' language proficiency as well as expanding their knowledge horizon. Accordingly, literature seems to provide answers for the question posed by the $4^{\text {th }}$ UAD TEFL International Conference: how to teach English in order to boost students' language proficiency while empowering them with knowledge, skills and attitude in endorsing sustainable development and promoting global awareness. In this article I will share my experience from my literature class at PSU, where I deal with the concerned question. I use two main literary works, $A$ Street Cat Named Bob (2012), a biography by James Bowen and The Kite Runner (2003), a novel by Khaled Hosseini, to teach my students about human values such as love, loyalty, courage and social justice. At the same time, I introduce them to the world's current issues such as diaspora, immigration, war and the idea of multicultural society.
\end{abstract}

\section{INTRODUCTION}

Literature has been playing a significant role in language teaching since it offers a bountiful and extremely varied body of written material that deals with enduring human issues. Therefore, it facilitates in enhancing students' language proficiency as well as expanding their knowledge horizon. Regarding language proficiency, literature is an effective tool for empowering communicative competence either it be speaking, reading and writing skills. It is also ideal for reading comprehension since it encourages critical thinking. By doing so, it expands students' worldview and allows them to incorporate their own experience into the texts, hence they can enrich the meaning of the texts and contribute to the reading activities conducted in their classroom. Scholars Beach, Thein, and Webb (2012) highlight the benefits of literature as a tool for students to increase their experience of the world as follows:

Literature allows students to imaginatively step into alternative worlds, both like their own as well as far-distant, and gain understanding of self and others in rich social, cultural and historical contexts. From this perspective what matters most about the study of literature is not the memorization of different genres or forms or gaining passing familiarity with a canon of cultural monuments. Instead, you can select works that will address issues in their lives and the broader world (p. 137).

From the above quotation, we can see that literature can be effective instrument for students to gain insightful aspects of their own life and enhance their understanding of others. Apart from this, literature enriches the level of language comprehension and introduces students to terminologies they need in a professional level. Therefore, by reading literature, students experience language complexity and sophistication they hardly find in their everyday language. 
In the Thai context, even though English is introduced to students at a very young age and is a compulsory course at every level of education, it is still considered a foreign language. English is taught only as a subject at school and a number of Thai teachers have a low command of English, and they have a tendency to use Thai, instead of English, as a medium of instruction (Sangkapan, Boonprakarn, and Krairiksh, 2015). Therefore, students do not have much opportunity to use English in a classroom, let alone using it outside the classrooms.Moreover, a number of studies including Fowles (1996), Chianvichai (2002) and Kongprasert (2007) indicate that Thai students do not belong to a reading culture and that Thais are not book lovers. As a result, teaching and studying literature is one of the greatest challenges for both teachers and students. For teachers of literature, they have a hard time pushing their students to read and appreciate the beauty of literary language particularly if the students are not studying in the language or arts fields (Bonsom, Singhasiri and Vungthong, 2011).

Regarding this current situation, this article introduces a practical approach in order to assist in motivating students to appreciate literary texts and gain insightful knowledge about the narratives in the texts as well as improve their English proficiency. The literary texts introduced in this article also help expand students' perspective about life, people from other cultural backgrounds and the world different from their everyday circumstance. By adopting this approach and employing the suggested texts in a literary classroom, students learn how to bring out their energy and turn it into a creative force that helps them contribute to their society in a sustainable way.

\section{LITERATURE REVIEW}

\subsection{Benefits of Using Literature in the EFL Classrooms}

The reasons why literature is a beneficial tool in language learning has been a topic of discussion and scrutiny by scholars for decades. In terms of language acquisition, Povyey $(1967,41)$ suggests that "literature will increase all language skills because it will extend linguistic knowledge by giving evidence of extensive and subtle vocabulary usage, and complex syntax" (Cited in Bonsom, Singhasiri and Vungthong, 2011, 3). Widdowson (1975) highlights that a study of literature cannot be separated from a study of a language since they create "a sharp awareness of the communicate resources of the language being learnt" (Widdowson, 1975, 81). McKay (1982) and McRae (1994) argue that despite the current focus in ESL on meeting the particular academic and occupational needs of the students, the study of literature can contribute to such goals through the increase in reading proficiency, the promotion of interaction between reader and writer mediated through the text and the nurturing of abilities to decode the language and understand the concepts presented. Lazar (1993) asserts that literature can encourage language acquisition by providing meaningful contexts for processing and interpreting the new language. Hence it can be a way of supplementing the limited input of the classroom. As literature has various levels of meaning, students are required to share opinions and feelings in English. This can help accelerate their acquisition of language (Cited in Bonsom, Singhasiri and Vungthong, 2011, 3).

Regarding the content of literature, Frye $(1964,77)$ states that literature encourages tolerance among human beings, and as literature inspires imagination, it allows possibility and obliterates the concepts of rights and wrongs. Aleksandr Solzhenitsyn, in his1972 Nobel acceptance speech, highlights the intrinsic value of literature as follows: “[Literature] can overcome man's unfortunate trait of learning 
only through his own experience...recreating in the flesh what another has experienced, and allowing it to be acquired as one's own" (Cited in Brown and Stephens, 1995, 5). In addition, Larzar (1993) propounds that literature introduces students to a variety of themes and language usage. Unlike a narrative in course books, an intricate plot in a well-written novel can engage students and induce more powerful response from them. Moreover, literature enables students to understand the culture of people whose language they are using and encourage students to become aware of the social, political and historical events which form the background of literary texts written by authors living in many different countries (Larzar, 1993, 14-21 as cited in Bonsom, Singhasiri and Vungthong, 2011, 3). Brown and Stephens (1995) posit that while literature has a potential to celebrate the uniqueness of different cultures and their people, it also reaffirms the universal characteristics that define our humanity. Literature enables students to form their own self and connect them with the broader context of their society, their culture and their world (Brown and Stephens, 1995, 5).

Recent studies also confirm that literature is a subject of great advantages for EFL students of any field. Pison (2000) and Maley (2001) propose three benefits of using literature as a language teaching resource: linguistic, methodological and motivational. Linguistically, students are exposed to authentic language in various social and cultural contexts. The methodological benefit of literary texts permits various interpretations and therefore, encourages opportunities of interaction in the classroom. Finally, literature can motivate students to express their opinions, relate to the topics of discussion and identify with characters in the story (Cited in Bonsom, Singhasiri and Vungthong, 2011, 4).

2.2. English Language Teaching and Learning in the Deep South of Thailand: A Challenging Situation

In accordance with other EFL contexts, English in Thailand is taught as a subject in schools with limited opportunity for its use outside the classroom, especially in the rural areas of the country (Panyasi, 2015). The context of this paper is a literature class held at PSU, Pattani, which is a regional university situated in the deep south of Thailand, where the long-tern political struggles of separatist groups have resulted in enduring unrest situation in the area. Therefore, the situation is even more challenging comparing to other regions of the country. One of the differences between regional universities and those in large cities such as Bangkok is the opportunity to use English outside the classroom (Hayes, 2010). With the advancements of technology, students living or studying in regional schools and universities may have access to English media such as the Internet and satellite TV. Nonetheless, many still have limited opportunity to use English outside the classroom due to the lack of English environment and motivation to use English in their daily routine. In addition, there are limited opportunities for the students to use productive skills since the motivation to acquire knowledge of English mainly comes in a form of entertainment and receptive skills such as listening to English music, or watching English movies (Panyasi, 2015). In the context of the three southernmost provinces in which PSU, Pattani, is situated, the situation is more complicated. The long-lasting unrest, unsettling atmosphere, and the concern about safety result in the absence of native speaker teachers. Moreover, the troubling situation in the deep-south discourages students from other parts of the country to choose to study at PSU, Pattani. Consequently, the majority of students who enter the university come from local schools with relatively low standard of education. The majority of students have very limited background 
knowledge which does not meet university requirement. Many students in the liberal arts choose to study English just to improve their language proficiency instead of pursuing their knowledge at a tertiary level. As a result, for many of these students, the study of English literature is a challenging task both cognitively and linguistically.

2.3. How to Teach Human Values through English Literature: A Practical Approach

Regarding the challenges illustrated above, it is a great mission for literature teachers to encourage students to undertake the task of studying canonical literary works which requires a high level of English proficiency in every skill including critical thinking skill, and the knowledge of grammar. Hence, a new and more practical approach is required in order to help students comprehend what they read in the texts and to allow them to reap the fruit of their reading. Based on this idea, I decided to apply a collaborative learning approach and a project-based teaching strategy to facilitate students in their learning processes because they can work collaboratively with their peers. As Peterson and Miller highlights, "cooperative learning with students can lead to greater cognitive involvement, somewhat greater activation, and higher levels of motivation" (Peterson and Miller, 2004, 132). In addition, instead of using canonical texts which normally have unfamiliar settings, complicated plot and advanced level of English, I chose literary texts which are more relevant and appealing to students by using the texts that comprises the themes concerining basic human values which I believe are approachable for students. In doing so, it helps to enhance students' language proficiency as well as empower them with knowledge, skills, and attitude in endorsing sustainable development and promoting global awareness.

\section{METHODS}

\subsection{Course Materials}

Instead of using classic and canonical literary works, I chose more contemporary literary texts with the narratives and the themes that are relevant to student language and cultural backgrounds. James Bowen's A Street Cat Named Bob (2012), and Khaled Hosseini's The Kite Runner (2003)are the two literary texts used in the Novels class, which is an elective course for English and non-English major students. The first text was chosen on the ground that it introduces students to a context of contemporary England, mostly in the capital city of London. The text is a biography of James Bowen, a former homeless and drug addict living in London. However, when he adopts a stray cat and names it Bob, his life changes forever. The heart-warming relationship between James and Bob helps heal their past traumatic lives and leads them to find their new hope. Set in the year 2007 in London, the text is also packed with examples of contemporary usage of everyday English vocabulary, idioms, terminologies as well as the knowledge of English cultures and aspects of lives of people living in the cosmopolitan city of London, especially the lives of the homeless who struggle to survive in the big city despite all challenges. It also has universal themes of love, compassion and relation between humans and animals as well as the themes of hope and social justice.

The second text is a novel set against the backdrop of racial and political conflicts in Afghanistan. Colonial invasions and tribal conflicts leave the country in a war-afflicted circumstance. The protagonist, Amir, and his father Baba, have to leave behind their affluent life, their property and their relatives, undergo great tribulations of being refugees in Pakistan, and become immigrants in the US. They 
eventually manage to resettle in their adopted homeland. The novel contains the universal themes of love between friends, parents and children, how to overcome fear, how cowardice results in unremitting guilt, how forgiveness and sacrifice help redeem one's soul. It also introduces readers to the notion of multiculturalism, the effects of war and the world current phenomenon of refugee, migration, immigration and diaspora. Both literary texts are ideal for teaching students the notion of basic human values either it be human dignity, friendship, forgiveness, responsibility and compassion. In sum, the literary texts used as teaching materials in the class comprise the elements that can help increase students' knowledge, skills and attitude that encourage them to achieve the goal of becoming a better human being who can contribute to society and make the world a better place to live.

3.2. Class condition and limitation

The Novels class consists of 42 students, the majority of them are English majors and those who choose English as their minor subject.

a. Concern:

1) The numbers of students registering for the class was beyond expectation. It was, therefore, challenging for the teacher to manage the class and to provide consulting hours for students for their termpaper and final project.

2) The literary texts are selected based on the standard text for intermediate and upper-intermediate level; however, the majority of students do not have the language proficiency suitable for the assigned literary texts.

b. Solution: Teamwork, collaborative learning and project-based approaches were introduced to facilitate students in their learning and boost up their confidence in order to accomplish their study tasks. These approaches also provide the teacher an opportunity to have a close relationship with students when holding consulting hours for their projects.

\subsection{Teaching Procedure}

\section{a. Assignment I: Oral presentations}

Students are assigned from the beginning of the semester to read two literary texts, one is for the first half of the semester and the other is for the second half. The actual task of reading is mostly done at home, but the students are assigned to form a group of 5-6 to prepare for their in-class oral presentations following the assigned chapters in each text. The focusing points in their presentations include plot summary, characters, conflicts, literary techniques, setting, tone, important quotations and additional information, such as video clips about the novels and the authors, the film adaptations of the novels, the cultural aspects, and the context of the novels.

b. Assignment II: Term paper

Students are required to work in a group of 5-6 to produce a five-page long term paper with the topic relevant to one of the themes of the novels, for instance, homelessness, love between humans and animals, immigration, multicultural society, the effects of war on human beings, etc.

c. Assignment III: Term project (From texts to context)

Students are required to do group work by interviewing people in Pattani who may share some elements with the characters in the novels or those who have contributed to promote human values, enhance understanding between human 
beings, bridge the gap of understanding for people from different backgrounds, lesson other people sufferings, or encourage the sustainable development of their society. After the interview, students are required to write a blog using wordpress.com as a platform to introduce interesting aspects of Pattani people and their culture to the outside world.

3.4. Evaluation

The semester lasted for 16 weeks and the course ran for 48 hours all together. Students were required to attend at least $80 \%$ of the classes. They were accessed from class attendance and participation (10\%), two group presentations (20\%), quizzes throughout the semester (30\%), one term paper $(10 \%)$, and an interview project and blog writing (30\%).

\section{FINDINGS AND DISCUSSION}

To answer the question of how to teach human values through literature in order to enhance students' language proficiency as well as to promote sustainable development and global awareness, the students' evaluation and feedbacks were collected via online evaluation forms provided by the faculty's assessment center.

\subsection{Results from the Comment Section}

From the comment section in which students were asked to give feedbacks to the course, the majority of the students who wrote the comments held very positive view of the course both in terms of the teaching approaches and the contents of the course. They were impressed by the teaching strategies that allowed them to develop their collaborative working skills. They were also empowered in terms of language proficiency as well as presentation and speaking skills. The course provided them an opportunity to develop their critical thinking skill and equipped them with analytical techniques which helped them look at the world from different perspectives. They also gained knowledge of different cultures and were motivated to contribute to their society. According to Larzar (1993), literature enables students to understand the culture of people whose language they are using and raises readers' awareness of the social, political and historical events which form the background of literary texts written by authors living in many different countries. In addition, they were encouraged to acquire further knowledge and to improve themselves both in cognitive and linguistic domains. The followings are some of the feedbacks students gave about the course. Note that students were allowed to write their comments both in Thai and in English. Therefore, the Thai versions have been translated into English and some serious grammatical errors in the English versions have been corrected to be more comprehensible. The feedback can be categorized into four particular domains as follows:

i. Literature helps to broaden worldview and promote social awareness

a. The course allows me to experience a wider world apart from my own.

b. Reading the novels makes me know different kinds of people as presented through the characters in the novels. I also learn about people and their cultures, in particular the cultures of the countries that I have never known before, such as Afghanistan and the country that I have very little knowledge about it, such as England.

c. I learned about the beautiful side of Afghanistan, its cultures and people by reading The Kite Runner.

d. I have learned about different cultures and society both in Asia, America and England. I want to learn more about social well-fare of people in different societies. 
e. This class gives me a chance to learn deeper about the three countries: England, America and Afghanistan, which are the settings and the backgrounds of the novels. This makes me become interested in the situation of those countries including social and political issues.

f. The contents taught in the class are absolutely captivating. Both novels teach me how to lead my life, how to look at the world with a positive attitude. I have learned about different cultures and society both in Asia, America and England.

g. The course makes me become a sensible and understanding person and be more receptive about people who are different from me.

h. The term paper and the final project also help me improve myself to work with other people and to learn about ordinary people who do small things but can affect society in a great way.

i. The term project helps me learn about people in Pattani who try to help other people even though they are only ordinary people like others in society.

j. This course changes me to become a new one. Before having a chance to read the novel, A Street Cat Named Bob, I didn't like cats at all. However, when I finished reading the book, I became a cat-lover. Who can insist its loving and heart-warming character?

k. I learned a lot about my own life and how to live my life so that I can benefit others in society. Reading the two novels is like I have read ten books altogether because I can learn about almost everything about human life.

ii. Literature enriches critical thinking skills

a. Your teaching strategies allow me to have a deep understanding of the novels. I have an opportunity to analyze the characters in the novels, the settings, the time and atmosphere and other elements of the novels in detail. I even use the strategies the teacher teaches in the class to analyze the TV series I am following.

b. The course encourages me to see things from different perspectives.

c. I can practice how to analyze each character and learn the reasons behind their actions. It makes me become a sensible and understanding person and be more receptive about people who are different from me.

d. I learned how to analyze the main characters and the plot of the novels. It was quite hard, but it was very fun.

e. The course helps me link the situation in the novels into the real situation in my life.

f. This course makes me curious about the causes and effects of the characters' behaviors on their lives. After I finished the course, it changed my way of reading novels and watching movies because I will focus on every character's background and also try to analyze them. In addition, this course allows me to incorporate all the subjects I have learned throughout my university life and apply them in my analysis and classroom discussions

g. This is a very difficult subject for me because I have to use my head to get into characters thinking and feeling at that moment, and it is even harder when I have to analyze everything from the novels to share with my classmates and to present my analytical works in front of the class. 
iii. Enhancing language's proficiency

a. This course does not only teach me how to read and understand the content of the novels, but also helps me improve my speaking and presentation skills. I used to be very shy and was afraid to talk in front of the public because I was afraid to make mistakes. You allow me to make a mistake without getting discouraged. As a result, I can improve my presentation and public speaking skills.

b. I never had a chance to finish reading a whole English novel like this before and never had an opportunity to deliver a long presentation in front of the class like what I did in your class. This course provides me a chance to improve my English skills as well as critical thinking skills.

c. The oral presentations make me become more confident and help me learn about public speaking skills. The teacher always encourages me to be brave to speak out and to improve my English.

d. Studying the two novels helps me improve my English skills a lot. It isn't only my reading, but also my writing, speaking, and presentation skill.

e. The oral presentations make me become more confident and help me learn about public speaking skills

iv. Developing collaborative learning skills

a. Brainstorming for my group work is the best activity that allows me to share my ideas and learn how to respect other people's ideas. I learn how to agree and disagree in order to come up with the best idea for the presentations, the term paper, and the final project.

b. The term paper and the final project help me improve myself to work with other people.

c. I also have a chance to work collaboratively with my friends. It makes me become a hard-working person.

\section{CONCLUSION}

To conclude, the Novels course, among other literary subjects, is one of the most challenging classes I have ever taught. The fact that the students have a wide range of language proficiency encouraged me to find strategies to approach them. In using collaborative learning and project-based strategies, I found that students have less anxiety and more relaxed when they have to undergo difficult tasks. This is because students do not have to endure the whole learning processes by themselves without the help from their friends. The purpose of introducing them to the new world beyond their daily routine through the narratives in the novels also helps expand their horizon. They learn how people can connect through shared human values even though they are different in terms of races, cultures and social standings. In addition, despite the fact that some students have difficulties expressing their ideas in English when they have to present in front of the classroom, they are provided with a platform to try and make mistakes without losing their confidence. In addition, the term project which allows them to learn about people in their own familiar community encourages them to contribute to the world around them. From this observation, it can be stated that students can always improve themselves both cognitively and linguistically if they are provided an opportunity to contribute to classroom activities and to generate their own ideas. They can also become more perceptive and more understanding if they are provided with analytical skills and knowledge of the world. Therefore, literature classroom is an ideal platform to teach basic human values to students 
and to encourage them to have social awareness and help to promote sustainable development among younger generations.

\section{REFERENCES}

Beach, R., Thein, A.H., \& Webb, A. (2012). Teaching to exceed the English language arts common core standards: A literary practices approach for 6-12 classrooms. New York, NY: Routledge.

Brown, J.E. and Stephens, E.C. (1995). Teaching young adult literature: Sharing the connection. USA: Wadsworth Publishing Company.

Bunsom, T.,Vungthong J, and Singhasiri, W. (2011). Developing engineering students' critical thinking skills through reading short stories. Journal of English Studies, 6, 118-140.

Bunsom, T., Singhasiri, W. and Vungthong, S. (2011). Teaching English literature in Thai universities: A case study at King Mongkut's University of Technology Thonburi. Proceedings of the 16th English in South-East Asia Conference: English for people empowerment. Sanata Dharma University, Indonesia. 2011. pp. 237-252.

Cheanvichai, K. (2002). Students' response to literary texts in the EFL classroom: an empirical study in the IELE, Assumption University, Bangkok. Dissertation.

Fowles (1996, April 4). Investigating Thai students' attitudes towards reading in English. Bangkok Post. Retrieved from http://www.bangkokpost.com

Kongprasert, T (2007). Book business in Thailand year 2007. Retrieved from http://www.thaiworld.org/en/thailand_monitor/answer.php?question_id $=627$

Larzar, G. (1993). Literature and language teaching: a guide for teachers and trainers. Cambridge: Cambridge University Press.

Maley, A. (2001). Literature in the language classroom. In R. Carter and D. Nunan (eds) The Cambridge Guide to TESOL. Cambridge: Cambridge University Press, 180-185.

Panyasi, Supinya. (2015). Teaching English literature to English as a second language learners. University of Technology, Sydney. PhD dissertation.

Peterson, S.E and Miller, J.A. (2004). Comparing the quality of students' experiences during cooperative learning and large-group instruction. The Journal of Educational Research, 97(3) (Jan. - Feb., 2004), pp. 123-133

Pison, R. (2000). Integrating language and literature: An approach to teaching literary texts. The ACELT Journal 4(1).

Sangkapan J., Boonprankarn, K., and Krairiksh W. (2015). Situations and problems in learning English at secondary schools affiliated with municipalities in three southern border provinces. Proceedings of the $6^{\text {th }}$ Hatyai National Academic Conference. Hatyai University, Thailand. 2015. pp. 270-284 Retrieved http://www.hu.ac.th/conference/ conference2015/proceedings/data/

Widdowson, H.G. (1975). Stylistics and the teaching of literature. Essex: Longman. 